\title{
Improvement of Fire Extinguishing Performance by Decentralized Supply of Fire-Fighting Agents
}

\author{
Yasushi Iwatani, Hiroyuki Torikai \\ Department of Science and Technology, Hirosaki University, Hirosaki, Japan \\ Email: iwatani@hirosaki-u.ac.jp
}

How to cite this paper: Iwatani, Y. and Torikai, H. (2017) Improvement of Fire Extinguishing Performance by Decentralized Supply of Fire-Fighting Agents. Open Journal of Safety Science and Technology, 7, 87-95.

https://doi.org/10.4236/ojsst.2017.73008

Received: June 2, 2017

Accepted: August 7, 2017

Published: August 10, 2017

Copyright $\odot 2017$ by authors and Scientific Research Publishing Inc. This work is licensed under the Creative Commons Attribution International License (CC BY 4.0).

http://creativecommons.org/licenses/by/4.0/

\begin{abstract}
One of the central problems in fire safety science and technology is to reduce damage caused by both fires and fire-fighting processes. This paper provides a potential solution to the problem, and it derives from decentralization of fire-fighting agents. In particular, this paper investigates fire extinguishing performance when a fire-fighting agent is supplied to a fire from one direction with one extinguisher and from two directions with two extinguishers. The two methods are called the centralized supply and the decentralized supply, respectively, in this paper. It is demonstrated that the decentralized supply reduces damage caused by both fires and fire-fighting processes. This follows from the facts that fire extinguishment by the decentralized supply is more certain than the centralized supply, and that the decentralized supply requires less total amount of a fire-fighting agent than the centralized supply for fire extinguishment.
\end{abstract}

\section{Keywords}

Fire-Fighting, Fire Safety Science, Decentralization

\section{Introduction}

Fire disasters can cause heavy damage to their surroundings including humans by combustion, heat, smoke and/or gas produced from fires. Undesired fires should be extinguished by using water or fire-fighting agents. However, firefighting processes usually produce other damage such as water damage or pollution by fire-fighting agents. If a fire is extinguished in short time by using a small amount of a fire-fighting agent, then it reduces the total damage produced by both the fire and the fire-fighting process. This is one of the central problems in 
fire safety science and technology. One approach to overcoming this problem is to create effective fire-fighting agents, and a number of studies have been reported on fire-fighting agents such as dry chemicals [1], wet chemicals [2] [3] and inert gases [4] [5] [6]. Another approach is to develop and improve firefighting equipments. For example, optimal shapes of spray nozzles have been investigated [7]. In another instance, the inert gas capsule increases fire-fighting ability and decreases the risk of human damage compared to direct spray of inert gas [8].

Although the ultimate objective in this research is same as the existing works, the approach in this research is different from them. In particular, this paper investigates two supplying methods of fire-fighting agents: one is the supply from one direction with one extinguisher, and the other is the supply from two directions with two extinguishers. The two methods are called the centralized supply and the decentralized supply, respectively, in this paper. This paper compares the fire extinguishing performance of the two supplying methods. Here, the inert gas capsule [8] is used for flame extinguishment, since the supplied amount of fire-fighting agents to flames can be easily specified.

The following two are demonstrated in this paper: 1) Fire extinguishment by the decentralized supply is more certain than the centralized supply. 2) The decentralized supply requires less total amount of a fire-fighting agent than the centralized supply for fire extinguishment. These two imply that the decentralized supply is more powerful than the centralized supply, and that the decentralized supply reduces damage caused by both fires and fire-fighting processes.

\section{Experimental Setup}

The extinguishing target is a diffusion flame established over a burner with a porous disk whose diameter and thickness are $100 \mathrm{~mm}$ and $10 \mathrm{~mm}$, respectively. The top surface of the burner is at $0.40 \mathrm{~m}$ height. The fuel is methane. It is supplied from a high pressure gas cylinder to the burner. In the burner, the fuel of methane passes through the porous disk, and it diffuses into the air with a uniform velocity distribution. The volumetric flow rate of methane is 10.0 litters/minute. It is regulated with a needle valve and measured with a flow meter (CMS0050, Azbil Corporation).

The inert gas capsule approach [8] is used for flame extinguishment, since the supplied amount of inert gas to the flame can be easily specified. In particular, rubber balloons are filled with an inert gas of helium, the balloons burst in a neighborhood of a flame by heat, and the inert gas flow is supplied to the flame with a large velocity which is caused by tension of the stretched rubber membranes. Each balloon is attached to a motion stage of a linear actuator so as to automatically transport the balloon to a neighborhood of a flame. The balloons are Hira-8-Maru-130 (Marusa Saito Gomu Corporation), and the linear actuators are ELS2X-E030-K2L-02 (ORIENTAL MOTOR Co., Ltd.). The inert gas capsule approach has the following three properties: 1) Inert gas as a fire-fight- 
ing agent produces extremely smaller damage than other fire-fighting agents such as water and fire-fighting powders. On the other hand, inert gas is not so powerful for fire extinguishment, and it is not often used in actual fire disasters. Improvement of the fire extinguishing performance of fire-fighting approaches with inert gas is very effective for reducing damage produced by fire-fighting processes. 2) In ordinary extinguishing approaches with inert gas, inert gas is usually supplied from some distance away from a fire, and hence the inert gas concentration decreases at the fire due to mixing with air. In the inert gas capsule approach, the inert gas in a rubber balloon is insulated from air, and the inert gas is not mixed with air until the burst of the balloon in a neighborhood of a fire. The inert gas capsule approach enhances the extinguishing performance of inert gas. 3) The inert gas capsule approach fits well into robotic fire-fighting [9] [10]. Performance analysis of the decentralized supply of inert gas capsules may provide an optimal fire-fighting strategy for robotic fire-fighting.

This paper investigates fire extinguishing performance of several experimental configurations and several volumes of helium in a balloon. The number of pairs of a balloon and a linear actuator is one or two for each trial. For each trial, the burner and linear actuators are located as one of four locations illustrated in Figure 1, where the linear actuators are maintained in a horizontal position and they move in a radial direction of a circle whose center corresponds to the burner center. Each location with two linear actuators is associated with the relative angle between the two linear actuators.

Our fire extinguishing test for the centralized supply with one balloon follows the following steps for each specified volume of helium:

1) A linear actuator is set as illustrated in Figure 1(a). A support frame that couples a balloon with the motion stage of the actuator is set at a height such

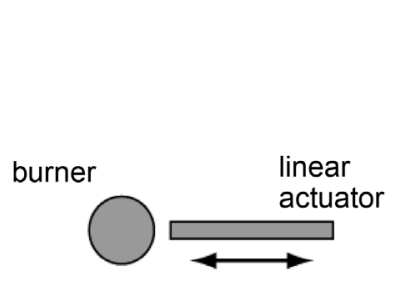

(a) single

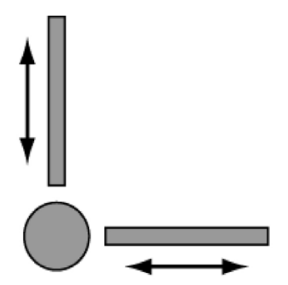

(b) $90^{\circ}$

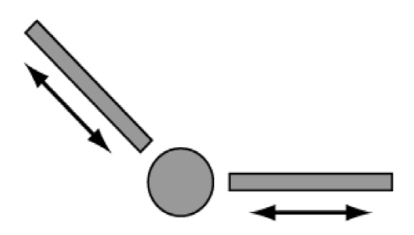

(b) $135^{\circ}$

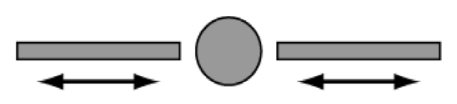

(d) $180^{\circ}$

Figure 1. Top views of four locations of the linear actuators for investigation of fire extinguishing performance. One linear actuator is located as (a). Two linear actuators are located as (b), (c) or (d), and their relative angles are different from each other. 
that the vertical center of balloons filled with the specified volume of helium corresponds to the top surface of the burner.

2) The following process is repeated ten times.

a) A balloon filled with the specified volume of helium is taped to the support frame.

b) The balloon is moved by hands until the balloon touches the burner as seen in the left top photo of Figure 2.

c) The balloon position is automatically controlled such that the balloon is moved $150 \mathrm{~mm}$ away from the burner.

d) The fuel of methane with a flow rate of 10.0 litters/minute is supplied to the burner, and a diffusion flame is produced over the burner as shown in the left bottom photo of Figure 2.

e) The balloon position is automatically controlled such that the balloon is moved $155 \mathrm{~mm}$ towards the burner center with a velocity of $100 \mathrm{~mm} / \mathrm{second}$.

f) See whether the flame is extinguished or not, and stop the supply of methane.

The same procedure is applied to the decentralized supply with two balloons. Each two balloons have equal volumes of helium in the decentralized supply. To simplify notation, the n $L$ decentralized supply denotes the decentralized supply with two balloons whose each volume of helium is $n / 2$ litters $(L)$. In the same fashion, the $\mathrm{n} L$ centralized supply denotes the centralized supply with a balloon filled with $n \mathrm{~L}$ of helium. The indicated volume in the supplying methods represents the total volume of helium at each trial, not the volume of each balloon, in both the centralized supply and the decentralized supply.

The balloon altitudes set at Step 1 are consistent with changes of the volume

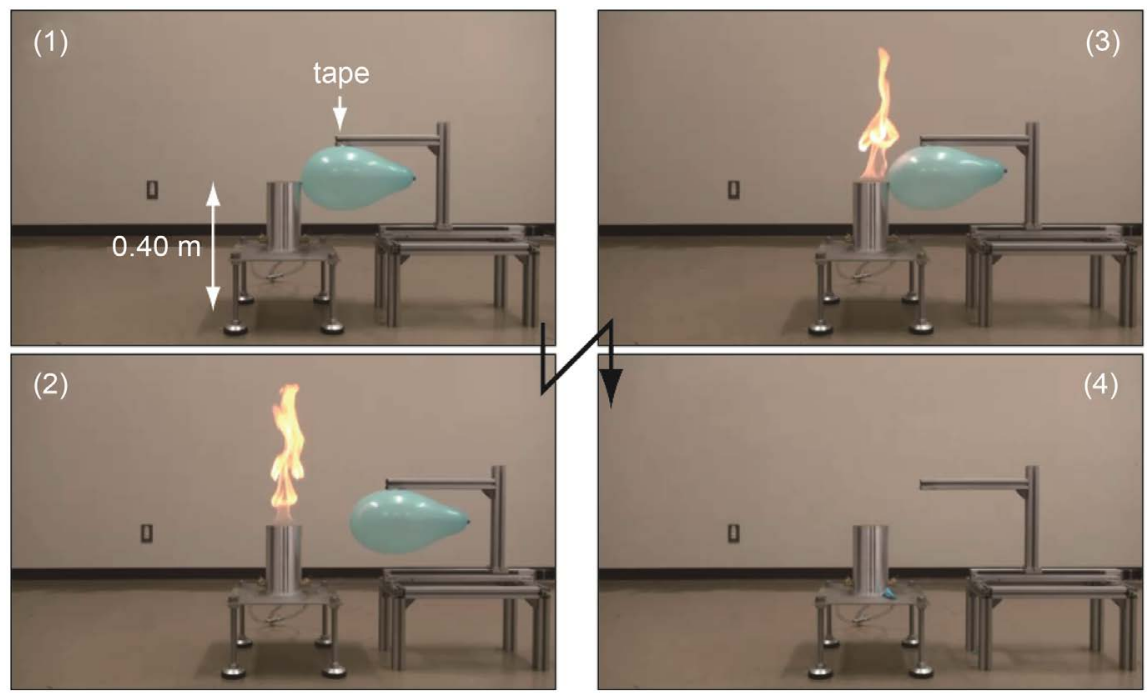

Figure 2. Experimental procedures for the fire extinguishing test: 1) A balloon touches the burner. 2) The balloon is moved $150 \mathrm{~mm}$ away from the burner, and a diffusion flame is produced. 3) The balloon is moved $155 \mathrm{~mm}$ towards the burner center, and it is contacted with the flame. 4) The balloon bursts. In this trial, the balloon was filled with $6 \mathrm{~L}$ of helium. 
of inert gas. The inert gas is mainly supplied to the flame base, even when the volume of the inert gas is changed.

The number of trials is fixed to be ten for each pair of the configuration and the volume of helium. The number of trials is according to our previous research [8], and it was sufficient to capture rough features of fire extinguishing performance.

The forward distance of the motion stage at Step 2-(e) is $5 \mathrm{~mm}$ longer than the backward distance at Step 2-(c). This is due to making certain contact between the balloon and the flame over the burner.

\section{Fire Extinguishing Performance}

For analysis of fire extinguishing performance, the extinguishment ratio $r$ is defined as

$$
r=n_{s} / n_{t},
$$

Where $n_{s}$ denotes the number of times that the flame is successfully extinguished, and $n_{t}$ is the number of trials. It is quantified as a number between 0 and 1 . The higher the extinguishment ratio, the more certain flame extinguishment is accomplished. The extinguishment ratio provides a quantitative index of fire extinguishing performance. Figure 3 summarizes fire extinguishing performance from a view point of the extinguishment ratio.

In the centralized supply, the extinguishment ratio monotonically increases until $3 \mathrm{~L}$ of helium, however, it does not for more than $3 \mathrm{~L}$ of helium. The extinguishment ratio does not achieve 1 , even if a large volume of helium is supplied to the flame by the centralized supply.

In the decentralized supply, there exist the following three combinations of balloon burst and flame extinguishment: 1) One balloon bursts, and the flame is extinguished. 2) Two balloons burst, and the flame is extinguished. 3) Two balloons burst, and the flame is not extinguished. The direct expectations of the extinguishment ratios of the decentralized supply generated from ones of the cen-

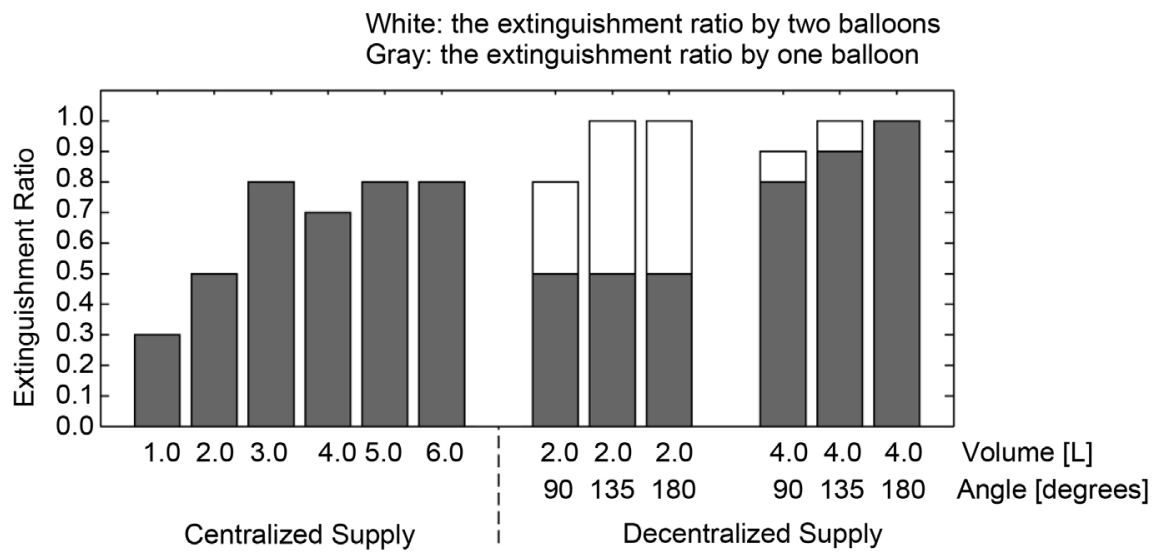

Figure 3. Resulted extinguishment ratios, where the volume means the total volume of helium and the angle denotes the relative angle of the two linear actuators. 
tralized supply are given by 0.51 and 0.75 for the $2 \mathrm{~L}$ and $4 \mathrm{~L}$ decentralized supplies, respectively.

All of the experimental extinguishment ratios in the decentralized supply are higher than or equal to 0.8 , and they are higher than the expectations directly generated from the extinguishment ratios of the centralized supply. They are also higher than or equal to any one in the centralized supply. The extinguishment ratio achieves 1 , when the relative angle of two linear actuators is 135 or 180 degrees. The result implies that the decentralized supply provides more certain extinguishment than the centralized supply.

In addition, all of the extinguishment ratios in the decentralized supply are higher than ones in the centralized supply, if the total supplied volumes of helium are equal to each other. The extinguishment ratios of the decentralized supply with 135 and 180 degrees achieve 1, although ones of the centralized supply do not. The result implies that the decentralized supply requires less total amount of a fire-fighting agent than the centralized supply for fire extinguishment.

The performance improvement derives from the following two.

One is a topographic effect. When one balloon bursts in the centralized supply, the inert gas of helium spreads into the flame or the air with no restrictions. The gas flow in the decentralized supply is different from the centralized supply. If the two balloons burst almost at the same moment, then the gas flows from the two balloons are affected each other. Otherwise if the two balloons do not burst at the same moment, then the gas flow from the first bursting balloon is affected by the other remaining balloon. In the both two cases, some inert gas flow supplied from the first bursting balloon may be redirected to the flame again by the other remaining balloon or by the gas flow supplied from the other balloon. The topographic effect improves the fire extinguishing performance by the first bursting balloon as confirmed in Figure 3, where the extinguishment ratios by one balloon in the decentralized supply are higher than ones in the centralized supply, if each balloon has the same volume of helium.

The other is cooperation of two balloons as seen in Figure 4.

In the trial, the two balloons did not burst at the same moment. The right balloon first burst, and the left one then burst. The right one did not accomplish extinguishment completely. The flame remained slightly after the burst of the right one, and the remaining flame got larger with time. The flame was extinguished by the left one, before it grew up large enough not to be extinguished. The cooperative effect increases fire extinguishing performance by the second bursting balloon, as confirmed at the $2 \mathrm{~L}$ decentralized supply in Figure 3 .

At last, let us discuss an optimal location of two extinguishers in the decentralized supply. The three locations of the two linear actuators are evaluated as follows: 1) The higher the extinguishment ratio is, the better the location is. 2) If the extinguishment ratios of two locations are same, the higher the extinguishment ratio by one balloon is, the better the location is. The second is introduced, 

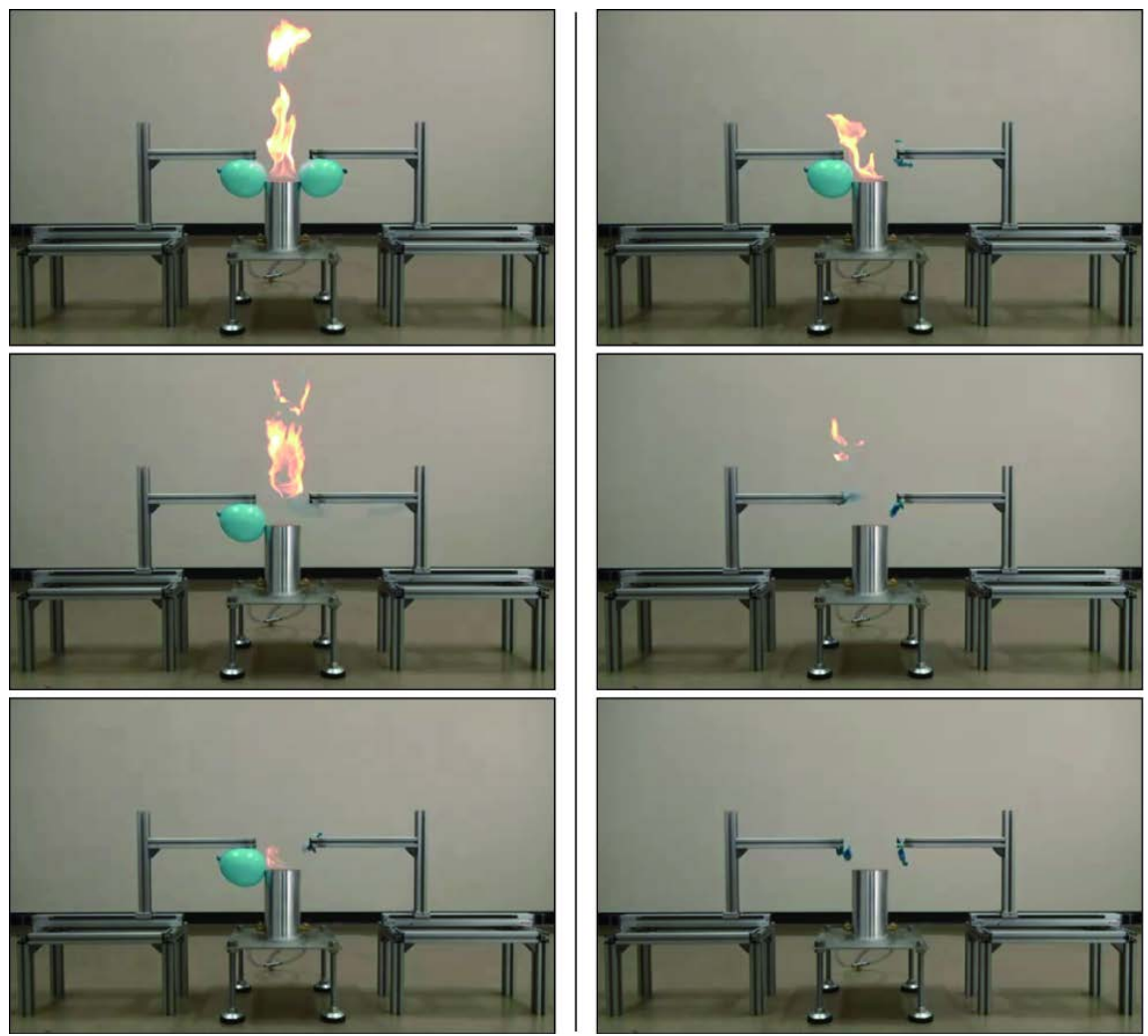

Figure 4. A cooperative extinguishment process by two balloons filled with $1 \mathrm{~L}$ of helium for each. The photos were taken every 0.167 seconds, and they ordered from top to bottom then left to right.

since flame extinguishment by one balloon produces a less amount of released gas and a less environmental pollution than two balloons. It is seen from Figure 3 that the fire extinguishing performance is maximized when the relative angle of is 180 degrees. The performance decreases, as the relative angle approaches to 0 degree. It is reasonable to consider that the optimal location derives from the topographic effect. However, the optimality is not clear for the $2 \mathrm{~L}$ decentralized supply, and it remains as an open issue that should be solved in the future by more investigation.

\section{Conclusions}

This paper has demonstrated that the decentralized supply is more powerful than the centralized supply in the following two senses: 1) Fire extinguishment by the decentralized supply is more certain than the centralized supply. 2) The decentralized supply requires less total amount of a fire-fighting agent than the centralized supply for fire extinguishment. These two imply that the decentralized supply reduces damage caused by both fires and fire-fighting processes.

The performance improvement can be explained by a topographic effect and a cooperative effect. Although the experimental results have been given by the inert gas capsule approach in this paper, it is supposed that the two effects do not depend heavily on fire-fighting agents or approaches. Thus, the improvement of 
fire extinguishing performance can be expected to appear in other fire-fighting agents or approaches, while the inert gas capsule approach was adopted for flame extinguishment in this paper.

At last, an optimal location of two extinguishers has been investigated in this paper, although additional discussion is required to make the conclusion certain. It is conjectured that the fire extinguishing performance with two extinguishers is maximized, when the two extinguishers are directed to a fire from opposite sides of the fire. If this is true, the optimal location cannot be realized by human for safety reasons. If two persons face each other across a fire and supply a fire-fighting agent to the fire, then the supplied agent or the fire fanned by the supplied agent may attack the fire-fighting persons. On the other hand, the location can be realized by fire-fighting robots such as ones discussed in [11]. In addition, disposal fire-fighting robots [9] [10] are suitable for the optimal location. The discussion on the optimal location of fire extinguishers may provide a new reason for developing fire-fighting robots, especially disposal fire-fighting robots.

\section{Acknowledgements}

This work was partially supported by JSPS KAKENHI Grant Number 17K01286.

\section{References}

[1] Ni, X., Kuang, K., Yang, D., Jin, X. and Liao, G. (2009) A New Type of Fire Suppressant Powder of $\mathrm{NaHCO}_{3} /$ Zeolite Nanocomposites with Core-Shell Structure. Fire Safety Journal, 44, 968-975. https://doi.org/10.1016/j.firesaf.2009.06.004

[2] Kim, A. (2011) Advances in Fire Suppression Systems. Construction Technology Updates, 75. https://www.nrc-cnrc.gc.ca/ctu-sc/files/doc/ctu-sc/ctu-n75_eng.pdf

[3] Koshiba, Y., Takahashi, Y. and Ohtani, H. (2012) Flame Suppression Ability of Metallocenes (Nickelocene, Cobaltcene, Ferrocene, Manganocene, and Chromocene). Fire Safety Journal, 51, 10-17. https://doi.org/10.1016/j.firesaf.2012.02.008

[4] Saito, S., Ogawa, Y., Saso, Y., Liao, C. and Sakei, R. (1996) Flame-Extinguishing Concentrations and Peak Concentrations of $\mathrm{N}_{2}, \mathrm{Ar}, \mathrm{CO}_{2}$ and Their Mixtures for Hydrocarbon Fuels. Fire Safety Journal, 27, 185-200.

[5] Senecal, J. (2005) Flame Extinguishing in the Cup-Burner by Inert Gases. Fire Safety Journal, 40, 579-591. https://doi.org/10.1016/j.firesaf.2005.05.008

[6] Senecal, J. (2008) Standardizing the Measurement of Minimum Extinguishing Concentrations of Gaseous Agents. Fire Technology, 44, 207-220.

[7] Grant, G., Brenton, J. and Drysdale, D. (2000) Fire Suppression by Water Sprays. Progress in Energy and Combustion Science, 26, 79-130. https://doi.org/10.1016/S0360-1285(99)00012-X

[8] Torikai, H., Narita, M. and Ito, A. (2013) Extinguishment of Pool Fire with Rubber Balloon Inflated with Inert Gas. The 24th International Symposium on Transport Phenomena, 682-688.

[9] Iwatani, Y. and Torikai, H. (2014) Development and Control of an Aerial Extinguisher with an Inert Gas Capsule. SICE Journal of Control, Measurement, and 
System Integration, 7, 168-172.

[10] Iwatani, Y. and Torikai, H. (2015) Flame Extinguishment by Cooperation of Two Aerial Extinguishers. IEEE/SICE International Symposium on System Integration, 534-539. https://doi.org/10.1109/sii.2015.7405036

[11] Lattimer, B.Y. (2015) Robotics in Firefighting. Emerging Trends, 100. http://www.sfpe.org/?page=FPE_ET_Issue_100

Submit or recommend next manuscript to SCIRP and we will provide best service for you:

Accepting pre-submission inquiries through Email, Facebook, LinkedIn, Twitter, etc. A wide selection of journals (inclusive of 9 subjects, more than 200 journals)

Providing 24-hour high-quality service

User-friendly online submission system

Fair and swift peer-review system

Efficient typesetting and proofreading procedure

Display of the result of downloads and visits, as well as the number of cited articles Maximum dissemination of your research work

Submit your manuscript at: http://papersubmission.scirp.org/

Or contact ojsst@scirp.org 